\title{
Mothers Characters and Adolescence Depression
}

\author{
Fezeh Jafari, Zahra Yousefi*, Golam-Reza Manshaee \\ Department of Psychology, Isfahan Science and Research Branch, Islamic Azad University, Isfahan, Iran \\ Email: jafari@yahoo.com, z.yousefi85@yahoo.com, saeedmansaee@yahoo.com
}

Received 21 March 2014; revised 28 April 2014; accepted 6 May 2014

Copyright (C) 2014 by authors and Scientific Research Publishing Inc.

This work is licensed under the Creative Commons Attribution International License (CC BY). http://creativecommons.org/licenses/by/4.0/

cC) (i) Open Access

\begin{abstract}
The aim of this study was to determine the relationship between forgiveness and rumination of mothers with depression symptoms in adolescent girls of Isfahan high schools. The sample consisted of 260 high school's students along with their mothers who were selected through multistage cluster sampling method. The research instruments were depression, forgiveness, and rumination questionnaires. The data were analyzed by statistical method including Pearson correlation and multiple regressions. The results indicated that rumination of mothers has a significant and positive relationship with depression of adolescents and forgiveness of mothers has a negative and significant relationship with depression. The Stepwise regression results indicated that rumination is able to predict depression. Regarding to results, it seems that decrease of mothers' rumination can be efficient in improving of depression of adolescent.
\end{abstract}

\section{Keywords}

\section{Depression, Forgiveness, Rumination}

\section{Introduction}

Depression is a common mental disorder that presents with depressed mood (e.g., feelings of sadness, loneliness, and crying), loss of interest or pleasure, decreased energy, feelings of guilt or low self-worth, disturbed sleep or appetite, and poor concentration.

Over the past years, more and more evidence has shown that depression is a serious mental health issue that can affect even very young children (Shugart \& Lopez, 2002). The pre-pubertal age depression rates for boys and girls are similar, and doubled in females after puberty (Costello, Mustillo, Erkanli, Keeler, \& Angold, 2003; Dopheide, 2006). Depression may adversely affect an individual’s academic achievement, social and familial

\footnotetext{
"Corresponding author.
} 
relationships, contribute to health problems, and increase his or her risk for suicide and substance abuse.

Given the prevalence of depression and the problems it creates, investigators have spent a great deal of effort to identify factors that may be useful for improving its detection and diagnosis. Factors affecting development and predisposition to depression are numerous (Hankin, 2006). Biomedical and psychosocial risk factors include a family history of depression, female sex, childhood abuse or neglect, stressful life events, and chronic illness.

Family factors are one of the most important causes of depressions in children, therefore family discords and parent's depression, as significant factors are investigated for children depression (Wang \& Crane, 2001). Huntsman (2008) delineated the relation between parent's mental illness and misbehavior with child. The children whose parents had mental illness were subject to a high risk of unfavorable consequences, including the disease like depression stress and polarization.

Researches have told that one of the most supported predictors of depression in youth has been having a depressed mother (Hammen \& Brennan, 2001). It is plausible that children's depressive symptoms occurred in reaction to their mothers' depressive symptoms. For instance, Hammen (2002) speculates that younger children may become distressed by their parents' low energy or apathy, while older children may become concerned about parents' expressions of worthlessness, hopelessness, or suicide ideation.

A meta-analysis of observational studies linking maternal depression and parenting behavior indicates that maternal depression is associated with increases in negative and hostile exchanges between mothers and their children, maternal disengagement from their children, and decreases in positive mother-child social interactions (Lovejoy, Graczyk, O’Hare, \& Neuman, 2000).

Many researchers have agreed that the quality of parenting every child received would have a significant impact on the extent to which the child matured into a functioning adult (Brennan et al., 2000; Hammen, Shih, \& Brennan, 2004). Numerous studies have shown that maternal depression has a greater negative impact on daughters than that on sons (Davies \& Windle, 1997; Duggal, Carlson, Sroufe, \& Egeland, 2001). Girls often spend more time with their mothers (Montemayor, 1983), have a more dependent emotional connection with parental figures (Goodman \& Gotlib, 2002) and also have greater conflicts with their mothers (Hill, Holmbeck, Marlow, Green, \& Lynch, 1985; Steinberg, 1987, 1988). Therefore it seems that the girls whose parents have mental illness are subject to a high risk of depression.

The purpose of this research is to investigate the relationship between mothers' forgiveness and rumination with depression symptoms in adolescent girls. It is hypothesized that mothers' rumination will increases adolescents' depression and in contrast mothers' forgiveness will decreases adolescents' depression.

\section{Rumination}

Rumination, defined as negative repetitive thoughts, is a symptom that is commonly related to depression (Verhaeghen, Joormann, \& Khan, 2005) and is associated with feelings of helplessness. According to the response styles theory (Nolen-Hoeksema, 1991), rumination is a mode of responding to distress that involves repetitively and passively focusing on symptoms of distress and on the possible causes and consequences of these symptoms. Rumination is correlated with a variety of maladaptive cognitive styles, including negative inferential or attributive styles, dysfunctional attitudes, hopelessness, pessimism, self-criticism, low mastery, dependency, and neuroticism (Ciesla \& Roberts, 2002; Flett, Madorsky, Hewitt, \& Heisel, 2002; Lam, Smith, Checkley, Rijsdijk, \& Sham, 2003; Lyubomirsky \& Nolen-Hoeksema, 1995; Lyubomirsky, Tucker, Caldwell, \& Berg, 1999; NolenHoeksema \& Davis, 1999; Nolen-Hoeksema \& Jackson, 2001; Nolen-Hoeksema, Larson, \& Grayson, 1999; Robinson \& Alloy, 2003; Spasojevic \& Alloy, 2001).

There are many reasons why mothers' rumination symptoms may lead to depression and rumination in adolescents. Depressed mothers may be more likely to model ruminative behaviours for their children and/or encourage rumination as a coping strategy via direct instruction. A mother who ruminates out loud about her own problems can certainly teach a child how to ruminate through modeling (Grimbos, Granic, \& Pepler, 2013). In a recent study, it was found that mothers' encouragement of emotional expression while their children played a stressful task led to the development of depressive rumination in daughters (Cox, Mezulis, \& Hyde, 2010).

\section{Forgiveness}

Forgiveness is a process that involves a change in emotion and attitude regarding an offender. McCullough and his colleagues (1998) conceptualized forgiveness as a motivational phenomenon. They described forgiveness as 
"the reduction in avoidance and revenge motivation following an interpersonal offense (p. 1603)", thus placing greater emphasis on behavior, albeit triggered by emotions.

Forgivingness can be construed as a human strength or personality trait with positive consequences for individuals and social relationships. Specifically, forgiveness is the change process by which an individual becomes more positively disposed and less negatively disposed toward an individual who has harmed him or her at some point in the past.

Correlational studies have shown that forgiveness is positively associated with mental health (Berry \& Worthington, 2001), positive affect (Thompson et al., 2005), and life satisfaction (Brown \& Phillips, 2005; LawlerRow \& Piferi, 2006; Thompson et al., 2005), and negatively associated with depression (Berry, Worthington, O’Connor, Parrott, \& Wade, 2005; Brown \& Phillips, 2005; Lawler-Row \& Piferi, 2006; Orcutt, 2006).

Transgressions are part of normal childhood development, and parents' knowledge of this fact can further cause forgiveness of children to be viewed as a necessary, moral requirement of the parental role. When children cannot earn mothers' forgiveness for small mistakes, they will begin to feel worthless. Forgiveness is very important to trust in the parent-child relationship.

\section{Method}

\subsection{Participants}

Study participants included 260 high school's students along with their mothers who were selected through Multi-stage cluster sampling method. For sampling, from six education districts, 3 districts and from each district 3 schools were randomly selected, and then three classes were selected from each school. All selected students completed the Kutcher adolescent depression questionnaire and their mothers filled out the Heartland forgiveness Scale and rumination questionnaires.

\subsection{Instruments}

Kutcher Adolescent Depression Scale. It is a psychological self-rating scale developed by Kutcher. It has 11 items and responses are scored on a 4 point scale. There are ten questions about depression symptom frequency that the patient rates on a straight 4 point scale according to the following choices: "hardly ever", "much of the time", "most of the time", "all the time", and one question relating to the severity of suicidal ideation. Scores on the test range from 0 to 33. Unlike some rating scales, there is no threshold for sub-clinical presentation, or ranges for mild, moderate, and severe symptoms. Higher scores simply indicate more severe current depression symptoms (Kutcher, 2003). In the present study, internal consistency was assessed. Cronbach's alpha for the present sample was .83 .

The Heartland Forgiveness Scale. The Heartland Forgiveness Scale (HFS) is a self-report measure consists of 18 items that examines dispositional forgiveness of self (Items 1 to 6), others (Items 7 to 12), and situations (Items 13 to 18) (Thompson et al., 2005). Participants rate each item on a 7 point Likert scale ranging from $1=$ "almost always false of me" to 7 = "almost always true of me". Higher scores indicate higher levels of forgiveness, and lower scores indicate lower levels of forgiveness. The scale overall was found to have good internal reliability with a Cronbach's alpha coefficient of .87 and good validity being positively correlated with measures of hope, cognitive flexibility, relationship satisfaction, and social desirability (Thompson \& Snyder, 2003). In the present study, internal consistency was assessed. Cronbach's alpha for the present sample was .82.

Rumination. The rumination scale (Yousefi et al., 2009) consists of 39 items and five subscales (Broodding $=12$ items, Self-blame $=10$ items, Rumination symptom-based $=7$ items, Introspection $=5$ items, Rumination about possible causes of depressed mood $=5$ items). Each items is rated on a five-point scale from $1=$ not at all to $5=$ very high. The rumination scale has demonstrated a high level of internal consistency (Cronbach's alpha $=.93$ ) as well as a high level of test retest reliability (.78) in a sample of university students (Yousefi et al., 2009). In the present study, internal consistency was assessed. Cronbach’s alpha for the present sample was .90.

\section{Results}

To response to research questions, data was examined in two steps. The first step was to examine the intercorrelations matrix between dependent and independent variables (Table 1). The results showed adolescence depression was significantly and meaningfully associated with mother rumination $(r=.297, p=.001)$ and mother for- 
giveness $(\mathrm{r}=.136, p=.040)$. The second step was predicting adolescence depression by mother's characters.

\section{Predicting Adolescence Depression}

Multiple regression analyses was conducted to responses research questions in relation to predicting adolescence depression. Adolescence depression was entered as the dependent variable, secure, dependent, anxiety attachment styles, forgiveness and rumination were entered as the independent variables. Summary data of multiple regressions are presented in Table 2.

The results indicated a significant model fit, $\mathrm{F}=15.33, p=.001$, and that the independent variable (rumination) included in the model was able to account for $8.8 \%$ of the variance $\left(\mathrm{R}^{2}=.088\right)$.

The results show significant positive regression beta weight for rumination $(\beta=.297, p<.001)$, an indicator that mothers with higher levels of rumination are expected to have adolescents with higher score in depression.

\section{Discussion}

The main objective of this study was to determine the relationship between forgiveness and rumination of mothers with depression symptoms in adolescent girls. The results showed that rumination of mothers was positively and meaningfully associated with depression symptoms in adolescent girls. These results concur with the findings of previous research.

There are a multitude of reasons why mothers' rumination symptoms may lead to depression in adolescents. Mother's rumination can influence her attention to and awareness of her children's need and can also interfere with her ability to process social information efficiently and accurately. Her negative affective bias may create tendencies to misinterpret child behavior, and they may be inclined to attribute negative intentions and motives to their children's behavior. Whether directly or indirectly, each of these psychosocial stressors negatively impacts the quality of the mother-child relationship and elevates children's levels of stress which can lead to depression.

The results also showed that mothers' forgiveness was negatively and meaningfully associated with depression symptoms in adolescent girls.

When children cannot earn mothers' forgiveness for small mistakes, they will begin to feel worthless. They will also never learn how to truly offer their own forgiveness to others, including parents. Forgiveness is very important to trust in the parent-child relationship. Without the ability to forgive those mistakes, there will be little trust in their relationship.

Trust in parents will build their self-esteem, and a good self-esteem will lend itself to finding forgiveness for others in their adult lives. In addition, growth in trust is effective in decreasing anxiety and fear in children.

Forgiveness has been hypothesized to be facilitated by positive emotions associated with love and altruism (McCullough et al., 1998). Mothers can assist their children in their character development by teaching them to be understanding and forgiving when angry.

Table 1. Means, Standard Deviations and Pearson correlations for dependent and independent variables. $\mathrm{N}=160$.

\begin{tabular}{cccccccccc}
\hline Variables & $\mathbf{M}$ & SD & $\mathbf{1}$ & $\mathbf{2}$ & $\mathbf{3}$ & $\mathbf{4}$ & $\mathbf{5}$ & $\mathbf{6}$ \\
\hline 1-Adolescence depression & 20.33 & 5.63 & 1 & $.297 "$ & .022 & -.044 & .015 & $.136^{\prime}$ \\
2-Rumination & 43.93 & 11.84 & & 1 & -.010 & $.223^{\prime \prime}$ & -.103 & $.341^{\prime \prime}$ \\
3-Secure attachment & 20.95 & 3.80 & & & 1 & $-.151^{\prime \prime}$ & $.260^{\prime \prime}$ & $.229^{\prime \prime}$ \\
4-Dependent attachment & 16.05 & 4.16 & & & & & & -.060 & $.327^{\prime \prime}$ \\
5-Anxiety attachment & 17.11 & 4.02 & & & & & & -.267 \\
6-Forgiveness & 59.21 & 13.51 & & & & & & 1 & 1 \\
\hline
\end{tabular}

Note: " $=p=.001 ;{ }^{\prime}=p=.05 ; \mathrm{N}=160$.

Table 2. Stepwise multiple regression of adolescence depression based on rumination and forgiveness.

\begin{tabular}{cccccccc}
\hline Independent variable & & Model & B & SEB & $\beta$ & Sig. \\
\hline Adolescence depression & 1 & rumination & .141 & .036 & .297 & 3.91 \\
\hline
\end{tabular}


Forgiveness is a highly effective virtue in diminishing the excessive anger and sadness that is associated in most childhood depression. Forgiveness can reduce excessive anger in children and in teenagers and may prevent the later development of psychiatric disorders by giving children and teenager a proven method for resolving anger.

\section{Conclusion}

In sum, it can be concluded that decrease of mothers' rumination and increase of forgiveness can be efficient in improving of adolescent depression because both of them are important factors in mother-child relationships and by improving them can decrease adolescent depression.

\section{References}

Berry, J. W., \& Worthington, E. L. (2001). Forgivingness, Relationship Quality, Stress While Imagining Relationship Events, and Physical and Mental Health. Journal of Counseling Psychology, 48, 447-455.

http://dx.doi.org/10.1037/0022-0167.48.4.447

Berry, J. W., Worthington, E. L., O’Connor, L. E., Parrott, L., \& Wade, N. G. (2005). Forgivingness, Vengeful Rumination, and Affective Traits. Journal of Personality, 73, 183-225. http://dx.doi.org/10.1111/j.1467-6494.2004.00308.x

Brennan, A. P., Hammen, C., Andersen, M. J., Bor, W., Najman, J. M., \& Williams, G. M. (2000). Chronicity, Severity, and Timing of Maternal Depressive Symptoms: Relationships with Child Outcomes at Age Five. Developmental Psychology, 36, 759-766. http://dx.doi.org/10.1037//0012-1649.36.6.759

Brown, R. P., \& Phillips, A. (2005). Letting Bygones Be Bygones: Further Evidence for the Validity of the Tendency to Forgive Scale. Personality and Individual Differences, 38, 627-638. http://dx.doi.org/10.1016/j.paid.2004.05.017

Ciesla, J. A., \& Roberts, J. E. (2002). Self-Directed thought and Response to Treatment for Depression: A Preliminary Investigation. Journal of Cognitive Psychotherapy, 16, 435-453.

Costello, E. J., Mustillo, S., Erkanli, A., Keeler, G., \& Angold, A. (2003). Prevalence and Development of Psychiatric Disorders in Childhood and Adolescence. Archives of General Psychiatry, 60, 837-844. http://dx.doi.org/10.1001/archpsyc.60.8.837

Cox, S. J., Mezulis, A. H., \& Hyde, J. S. (2010). The Influence of Child Gender Role and Maternal Feedback to Child Stress on the Emergence of the Gender Difference in Depressive Rumination in Adolescence. Developmental Psychology, 46, 842-852. http://dx.doi.org/10.1037/a0019813

Davies, P. T., \& Windle, M. (1997). Gender-Specific Pathways between Maternal Depressive Symptoms, Family Discord, and Adolescent Adjustment. Developmental Psychology, 33, 657-668. http://dx.doi.org/10.1037/0012-1649.33.4.657

Dopheide, J. A. (2006). Recognizing and Treating Depression in Children and Adolescents. American Journal of HealthSystem Pharmacy, 63, 233-241. http://dx.doi.org/10.2146/ajhp050264

Duggal, S., Carlson, E. A., Sroufe, L. A., \& Egeland, B. (2001). Depressive Symptomatology in Childhood and Adolescence. Development and Psychopathology, 13, 143-164. http://dx.doi.org/10.1017/S0954579401001109

Flett, G. L., Madorsky, D., Hewitt, P. L., \& Heisel, M. J. (2002). Perfectionism Cognitions, Rumination, and Psychological Distress. Journal of Rational-Emotive and Cognitive Behavior Therapy, 20, 33-47.

http://dx.doi.org/10.1023/A:1015128904007

Goodman, S. H. \& Gotlib, I. H. (Eds.) (2002) Children of Depressed Parents: Alternative Pathways to Risk for Psychopathology. Washington, DC: American Psychological Association Press.

Grimbos, T., Granic, I., \& Pepler, D. (2013). The Relation between Co-Rumination, Maternal Depressive Symptoms and Child Psychopathology. Journal of Psychopathology and Behavioral Assessment, 35, 335-345. http://dx.doi.org/10.1007/s10862-013-9342-9

Hammen, C. (2002). Context of Stress in Families of Children with Depressed Parents. In S. H. Goodman, \& I. H. Gotlib (Eds.), Children of Depressed Parents: Mechanisms of Risk and Implications for Treatment (pp. 175-199). Washington, DC: American Psychological Association. http://dx.doi.org/10.1037/10449-007

Hammen, C., \& Brennan, P. (2001). Depressed Adolescents of Depressed and Non-Depressed Mothers: Tests of an Interpersonal Impairment Hypothesis. Journal of Consulting and Clinical Psychology, 69, 284-294. http://dx.doi.org/10.1037/0022-006X.69.2.284

Hammen, C., Shih, J., \& Brennan, P. A. (2004). Intergenerational Transmission of Depression: Test of an Interpersonal Stress Model in a Community Sample. Journal of Consulting and Clinical Psychology, 72, 511-522.

http://dx.doi.org/10.1037/0022-006X.72.3.511

Hankin, B. L. (2006). Adolescent Depression: Description, Causes, and Interventions. Epilepsy \& Behavior, 8, 102-114. 
http://dx.doi.org/10.1016/j.yebeh.2005.10.012

Hill, J. P., Holmbeck, G. N., Marlow, L., Green, T. M., \& Lynch, M. E. (1985). Menarcheal Status and Parent-Child Relations in Families of Seventh-Grade Girls. Journal of Youth and Adolescence, 14, 301-316. http://dx.doi.org/10.1007/bf02089236

Huntsman, L. (2008). Parents with Mental Health Issues: Consequences for Children and Effectiveness of Interventions Designed to Assist Children and Their Families. Literature Review, p. 1-53.

Lam, D., Smith, N., Checkley, S., Rijsdijk, F., \& Sham, P. (2003). Effect of Neuroticism, Response Style and Information Processing on Depression Severity in a Clinically Depressed Sample. Psychological Medicine, 33, 469-479. http://dx.doi.org/10.1017/S0033291702007304

Lawler-Row, K. A., \& Piferi, R. L. (2006). The Forgiving Personality: Describing a Life Well Lived? Personality and Individual Differences, 41, 1009-1020. http://dx.doi.org/10.1016/j.paid.2006.04.007

Lovejoy, M. C., Graczyk, P. A., O’Hare, E., \& Neuman, G. (2000). Maternal Depression and Parenting Behavior: A MetaAnalytic Review. Clinical Psychology Review, 20, 561-592.

Lyubomirsky, S., \& Nolen-Hoeksema, S. (1995). Effects of Self-Focused Rumination on Negative Thinking and Interpersonal Problem Solving. Journal of Personality and Social Psychology, 69, 176-190. http://dx.doi.org/10.1037/0022-3514.69.1.176

Lyubomirsky, S., Tucker, K. L., Caldwell, N. D., \& Berg, K. (1999). Why Ruminators Are Poor Problem Solvers: Clues from the Phenomenology of Dysphoric Rumination. Journal of Personality and Social Psychology, 77, 1041-1060.

http://dx.doi.org/10.1037/0022-3514.77.5.1041

McCullough, M. E., Rachal, K. C., Sandage, S. J., Worthington Jr., E. L., Brown, S. W., \& Hight, T. L. (1998). Interpersonal Forgiving in Close Relationships II: Theoretical Elaboration and Measurement. Journal of Personality and Social Psychology, 75, 1586-1603. http://dx.doi.org/10.1037/0022-3514.75.6.1586

Montemayor, R. (1983). Parents and Adolescents in Conflict: All Families Some of the Time and Some Families Most of the Time. The Journal of Early Adolescence, 3, 83-103. http://dx.doi.org/10.1177/027243168331007

Nolen-Hoeksema, S. (1991). Responses to Depression and Their Effects on the Duration of Depressive Episodes. Journal of Abnormal Psychology, 100, 569-582. http://dx.doi.org/10.1037//0021-843X.100.4.569

Nolen-Hoeksema, S., \& Davis, C. G. (1999). “Thanks for Sharing That”: Ruminators and Their Social Support Networks. Journal of Personality and Social Psychology, 77, 801-814. http://dx.doi.org/10.1037/0022-3514.77.4.801

Nolen-Hoeksema, S., \& Jackson, B. (2001). Mediators of the Gender Difference in Rumination. Psychology of Women Quarterly, 25, 37-47. http://dx.doi.org/10.1111/1471-6402.00005

Nolen-Hoeksema, S., Larson, J., \& Grayson, C. (1999). Explaining the Gender Difference in Depressive Symptoms. Journal of Personality and Social Psychology, 77, 1061-1072. http://dx.doi.org/10.1037/0022-3514.77.5.1061

Orcutt, H. K. (2006). The Prospective Relationship of Interpersonal Forgiveness and Psychological Distress Symptoms among College Women. Journal of Counseling Psychology, 53, 350-361.

Robinson, L. A., \& Alloy, L. B. (2003). Negative Cognitive Styles and Stress-Reactive Rumination Interact to Predict Depression: A Prospective Study. Cognitive Therapy and Research, 27, 275-292. http://dx.doi.org/10.1023/A:1023914416469

Shugart, M. A., \& Lopez, E. M. (2002). Depression in Children and Adolescents. When “Moodiness” Merits Special Attention. Postgraduate Medicine, 112, 53-6, 59-61.

Spasojević, J., \& Alloy, L. B. (2001). Rumination as a Common Mechanism Relating Depressive Risk Factor to Depression. Emotion, 1, 25-37. http://dx.doi.org/10.1037/1528-3542.1.1.25

Steinberg, L. (1987). Recent Research on the Family at Adolescence: The Extent and Nature of Sex Differences. Journal of Youth and Adolescence, 16, 191-197. http://dx.doi.org/10.1007/BF02139090

Steinberg, L. (1988). Reciprocal Relation between Parent-Child Distance and Pubertal Maturation. Developmental Psychology, 24, 122-128. http://dx.doi.org/10.1037/0012-1649.24.1.122

Thompson, L. Y., \& Snyder, C. R. (2003). Measuring Forgiveness. In S. J. Lopez, \& C. R. Snyder (Eds.), Positive Psychological Assessment: A Handbook of Models and Measures (pp. 301-312). Washington DC: American Psychological Association. http://dx.doi.org/10.1037/10612-019

Thompson, L. Y., Snyder, C. R., Hoffman, L., Michael, S. T., Rasmussen, H. N., Billings, L. S., et al. (2005). Dispositional Forgiveness of Self, Others, and Situations. Journal of Personality, 73, 313-360.

http://dx.doi.org/10.1111/j.1467-6494.2005.00311.x

Verhaeghen, P., Joormann, J., \& Khan, R. (2005). Why We Sing the Blues: The Relation between Self-Reflective Rumination, Mood, and Creativity. Emotion, 5, 226-232. http://dx.doi.org/10.1037/1528-3542.5.2.226 
Wang, L. \& Crane, R. D. (2001). The Relationship between Marital Satisfaction, Marital Stability, Nuclear Family Triangulation and Childhood Depression. The American Journal of Family Therapy, 29, 337-341. http://dx.doi.org/10.1080/01926180126502

Yousefi, Z., Abedi, M. R, Bahrami, F., \& Mehrabi, H. A. (2009). Construction and Standardization of Depressive Rumination Inventory. Journal of Psychology, 49, 54. 